\author{
"Mircea cel Batran" Naval Academy Scientific Bulletin, Volume XIX - 2016 - Issue 2 \\ The journal is indexed in: PROQUEST / DOAJ / Crossref / EBSCOhost / INDEX COPERNICUS / DRJI / OAJI / \\ JOURNAL INDEX / I2OR / SCIENCE LIBRARY INDEX / Google Scholar / Academic Keys/ ROAD Open Access I \\ Academic Resources / Scientific Indexing Services / SCIPIO / JIFACTOR
}

\title{
GPS VERSUS ELORAN
}

\author{
${ }^{1}$ Romeo BOSNEAGU \\ ${ }^{1}$ Associated Professor, PhD, „Mircea cel Batran” Naval Academy Constanta, romeo-bosneagu@yahoo.com
}

\begin{abstract}
The purposes of today's radionavigation systems converge; they aim to maintain and improve the three fundamental qualitative parameters of the positioning process: precision; availability; integrity. Still oscilating, the position of the greatest positioning users seem to have convergent pathways, yet in their vision, future belongs to global satelite navigation systems, doubled by the serveces of the Loran-C system, and starting with the second decade of the twenty-first century by e-Loran
\end{abstract}

Keywords: satelit, GPS, eLoran, eNavigation

\section{INTRODUCTION}

Global positioning system is a navigational system based on artificial satellites that provides position information (position and time) regardless the meteorological conditions, everywhere on the globe or in space,where there is an unobstructed visual field of four or more satellites. The system provides important real-time information for military, civilians and comercial users worldwide. The G.P.S. satelite system's design is partially based on ground-based similar radionavigational systems such as LORAN and Decca, developed at the beginning of the 40's and used by the Royal British Navy during world war two.

In the year 1956, fizician Friedwardt Winterberg suggested a general rellativity test (he tryed to slow the time in a strong gravitational field) using exact atomic clocks placed in orbit in the artificial satellites.

Subsequent, the calculation using the general relativity theory revealed the fact that the GPS satellites clocks were out of phase to the command and control station's hour on ground so that it was necesary to introduct a GPS satellites time correction module.Monitoring radio transmissions of the satellite allowed, as a result of the Doppler effect, the precise localization of the satellite on his orbit. Starting from this problem, was possible solving the inverse problem, namely the determination of the terrestrial position of a GPS receiver finding the real position of the satellite (satellites).

The first functional satellite system was the Transit system, succesfully tested in the year of 1960. The system used a constellation of five satellites and it could provide an updated pozition round about once per hour.

\section{NAVSTAR SATELLITE SYSTEM GPS} WORLD LEADER IN SATELLITE NAVIGATION

The GPS project was developed starting with 1973 to outrun the limits of previous positioning systems, introducing innovative ideeas of the era,

DOI: 10.21279/1454-864X-16-12-003

(C) 2015. This work is licensed under the Creative Commons Attribution-Noncommercial-Share Alike 4.0 License. related to satellite navigation. GPS system is developed and operated by the U.S.A. Defense department and it works with a constellation of 24 satellites.It became operational in 1995.Navstar GPS system is a simplex system, from the satellites to the GPS reciever, where the period of time of the GPS signal is transformed in distance based on the propagation speed of the signal. The working principle of the system is the measurement of the inclined distances, or pseudo-distances (four pseudo-distances), that help to determine the position in three dimensions of the reciever.For the determination of real-time ship's position the GPS signal is encrypted, and the carrying frequencies are modulated in PRN code, that consists in binary sequences that can be identified without error.The determination of the pseudo-distances is made based on this reference code, that can be a precise code $P$ or standard C/A. In $\mathrm{P}$ code, the broadcasting frequency is $10.23 \mathrm{MHz}$, period-266 days.Each satellite is assigned with a time segment of 7 days, so that he can emit the same frequency and can be identified without doubt.This technique is so called Code Division Multiple Access-CDMA. Each code segment is brought to zero at midnight (00h UTC) between Saturdays and Sundays. In $\mathrm{C} / \mathrm{A}$ code the frequency of emission is $1.023 \mathrm{MHz}$, period of one milisecond ([1], [5]).

To be mentioned also the existency of other satellite positioning systems, operational or in development: russian satellite system GLONASS, european satellite system Galileo, indian satellite system, chinese satellite system, japanese satellite system (table 1).The strongest and used world-wide is the american satellite system

GPS constellation consists in six orbital planes of four satellites each.The satellites have circular orbits with hights of $20.200 \mathrm{Km}$ and inclination of 55 degrees.First NAVSTAR generation (launched between 1978 and 1985) included 11 satellites, NAVSTAR-GPS([1], [2]. 


\section{"Mircea cel Batran" Naval Academy Scientific Bulletin, Volume XIX - 2016 - Issue 2 The journal is indexed in: PROQUEST / DOAJ / Crossref / EBSCOhost / INDEX COPERNICUS / DRJI / OAJI / JOURNAL INDEX / I2OR / SCIENCE LIBRARY INDEX / Google Scholar / Academic Keys/ ROAD Open Access I Academic Resources / Scientific Indexing Services / SCIPIO / JIFACTOR}

followed by Navstar 2 (between 1989 and 1990), Navstar 2A (1990-1997), Navstar 2R(19972004), Navstar 2RM(2005-2008), Navstar 2F in present $([4,5])$.

Russian system GLONASS (Globalnaya Navigationnaya Sputnikova Sistema) uses a different configuration with three orbital planes of eight satellites each(plus two reserve satellites in each orbital plan, meaning a total of 30 satellites). The orbital planes are disposed at an angular diffrence of 120 degrees, and the satellites enrolled in one orbital plane are situated at an angle of 45 degrees one from another.Each satellite moves on a circular orbit at the hight of $19,100 \mathrm{Km}$ and inclined by 64.8 degrees. The satellites are uniquely identified by the so called ,slot number': first orbital plane contains the slots from 1-8, the second 9-16 and the third contains the slots from 17-24 ([1]).

GLONASS system is formed by 24 satellites, with a positioning precision of $20 \mathrm{~m}$ for civil beneficiaries and $10 \mathrm{~m}$ for military beneficiaries, with a probability of $95 \%$. First alternative of the satellite system GLONASS used Block II satellites stabilized triaxial,modernized as Block Ila, Block Ilb şi Block Ilv. Second version of the system, with the name of GLONASS-M develops starting with year 1990.Until 2007 were launched 14 satellites from the second generation, modernized, with a period of exploitation of 7 years.

The third version of the system, starting with 2011 until now with the name of GLONASS-K, is a modern version that uses satellites with an exploitation period of 10 years, with reduced mass (compared with the older versions).GLONASS-K emits also a signal for civil users that ensures differential signals for search and rescue at seaSAR.Throughthe usage of CDMA signals (Code Division Multiple Access), GLONASS-K variant becomes interoperational with the american system NAVSTAR-GPS.With a constellation of 18 satellites, GLONASS covers the hole Russian Federation and with 24 satellites the hole globe ([1], [26]).

Chinese satellite system in development uses 16 active satellites and covers almost the entire AsiaPacific region.Beidou satellite system is a regional developed in the period of 2000-2003 when were launched onto orbit 3 satellites. The system is conceived for two geostationary orbits with a third reserve.Horizontal calculated precision of the system is of $100 \mathrm{~m}$.Compass satellite system or Beidou 2 is projected as a global system, with a satellite constellation that will comprehend a number of 30 satellites, with work frequency of 2491,75 MHz and will cover the zone comprised between north latitude from 5-55 degrees and east longitude from 70-140 degrees.Its satellite constellation will comprehend 35 satellites, in an unique architecture that combines 5 geostationary satellites an 30 orbital satellites either at a medium altitude,either at a geostationary altitude and being grouped in three orbital planes.

European - in developmentsystem Galileo will comprehend 30 satellites, 27 operational and 3 reserves, that will fly on a circular orbit eith an altitude of 23,222 Km-totally three orbital planes inclined by 56 degrees up against the equator.GALILEO satellite system ensures 5 services ([12]):

- positioning-free,

- information regarding security of life at sea,

- encrypted comercial services-by payment,

- public services restricted for governmental authorized users

- search and rescue at sea services with a positioning precision at global level $\leq 3.5$.

Also, GALILEO ensures retransmision of danger messages toward COSPAS-SARSAT system (satellite system used in search and rescue operation at sea). There is also an agreement with the U.S.A. for the interoperation with the NAVSTAR GPS. GALILEO satellite system will transmit 10 navigational signals: 4 navigation signals E5a-E5b, frequencies $1164-1215 \mathrm{MHz}$; three navigation signals $E 6$, into frequencies 1260-1300 MHz; three signals E2,L1,E1, frequencies 1559-1591 MHz; a SAR signal, frequencies from 1544-1545 MHz.

The japanese - in development satellite system, is a regional and complementary one (will improve the accuracy of the GPS signal on Japan territory).The japanese satellite system QZSS(QuasiZenitSatelliteSystem) is formed by three satellites found out on the eliptical inclined orbits, visible from Japans territory, with an elevation angle of 60 degrees.Each satellite transmits six signals in L broadband: 3 in L1, one in L1, one in E6 one in L2 and one in L5.A signal will assure a submillimetrical precision, the signal in broadband E6 will assure commercial services, the others are compatible with the GPS ones in the L2C and L1C standards.

The indian - in development- system will include 3 geostationary satellites and 4 satellites situated on the geostationary inclined low orbits so that they're visible simultanuasly from the indian territory. IRNSS(Indian Regional Navigational Satelitte System) satellite system is,in fact, a regional system that emits signals in broadband L5 and $S$ for general services, in broadband L5 and $\mathrm{S}$ for positioning and in L5-restricted services. 
"Mircea cel Batran" Naval Academy Scientific Bulletin, Volume XIX - 2016 - Issue 2

The journal is indexed in: PROQUEST / DOAJ / Crossref / EBSCOhost / INDEX COPERNICUS / DRJI / OAJI / JOURNAL INDEX / I2OR / SCIENCE LIBRARY INDEX / Google Scholar / Academic Keys/ ROAD Open Access I Academic Resources / Scientific Indexing Services / SCIPIO / JIFACTOR

Table 1 Global and regional satellite systems

\begin{tabular}{|c|c|c|c|c|}
\hline System & Country & Function date & Number of satellites & Precision \\
\hline NAVSTAR & SUA & $\begin{array}{l}1 \text { since } 1995 \\
2 \text { since } 2012\end{array}$ & 24 active, 4 reserve & $3-15 m$ \\
\hline GPS & SUA & 1993 & 31 in function & up to $50 \mathrm{~m}$ for civil use \\
\hline GLONASS & $\begin{array}{l}\text { Russian } \\
\text { federation }\end{array}$ & $\begin{array}{l}1 \text { since } 1993 \\
2 \text { since } 2012\end{array}$ & 23 in function & $\begin{array}{c}\text { up to } 55 \text { m horizontal for } \\
\text { civil use }\end{array}$ \\
\hline GALILEO & $\begin{array}{l}\text { European } \\
\text { union }\end{array}$ & 2002 & $\begin{array}{c}2 \text { in function, } 30 \text { planing } \\
\text { to be }\end{array}$ & up to $7 \mathrm{~m}$ horizontal \\
\hline Beidou & R.P.China & 2012 (regional) & $\begin{array}{c}8 \text { in function, } 35 \text { planing } \\
\text { to be }\end{array}$ & $10 \mathrm{~m}$ for civil use \\
\hline QZSS & Japan & $\begin{array}{c}2013 \text { (first } \\
\text { launched satellite } \\
2010 \text { ) }\end{array}$ & $\begin{array}{c}1 \text { in function, } 8 \text { planing } \\
\text { to be }\end{array}$ & $\begin{array}{c}\text { up to } 1 \mathrm{~m} \text { in combination } \\
\text { with GPS }\end{array}$ \\
\hline IRNSS & India & 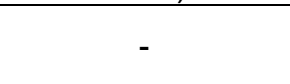 & $\begin{array}{c}7 \text { planing to be (3 GEO } \\
\text { and } 4 \text { MEO) }\end{array}$ & up to $20 \mathrm{~m}$ \\
\hline
\end{tabular}

During and right after WWII, positioning at sea was realized with the help of hyperbolical systems Decca,OMEGA and LORAN. Once with the entry in service of the satellite systems, the hyperbolical systems were closed, the only hyperbolical system still in use nowadays is LORAN system. The issue that appeared since then is:either to stop the system or to let in function the LORAN hyperbolical system. The pros are ([1], [2], [5], [21]):

- few users;

- dropped efficency compared to the costs;

- positioning informations from the satellite navigation systems are superior in precision;

- stability and distance to those assured by LORAN system.

Against arguments are ([2], [21]):

- the need of an indipendent functional system; technological evolution permits -upgrading the LORAN system;

- LORAN system uses a strong signal, hard to jam;

- LORAN is an indipendent system different from the satellite system, funcionally stabil complementary to the satellite navigation systems, with a day pass higher degree of accuracy.

3. MODERNIZATION OF LORAN HYPERBOLICAL NAVIGATION SYSTEM. ELORAN SYSTEM

The improved version of Loran-C system, or eLoran, was developed in the U.S.A. in the mid

DOI: 10.21279/1454-864X-16-12-003

(C) 2015. This work is licensed under the Creative Commons Attribution-Noncommercial-Share Alike 4.0 License. 90's. At that moment was simply a modernization and recapitalisation program of the Loran system by the U.S. Coast Guard, that wanted to find out if the system was efficient and if they could base on it also after the year 2000. e-Loran System is a major technological upgrade of Loran-C, but uses the same sites and technologie as Loran-C. Loran-C System represents, in the american and european radionavigation plan, the reserve of spatial positioning systems and will be kept functional. Updated eLoran (Enhanced LoraneLoran) is an international starndard 2D (bidimensional) positioning, navigation and time system (Positioning, Navigation, and Timing PNT), on the frequency of $100 \mathrm{kHz}$, for different types of transport and other positioning civil applications ([18]).

Hyperbolical navigation system eLoran is an independent hyperbolical system, different and complementary to the Global Navigation Sattelite Navigation System-GNSS. Radio technical commision for maritime services founded in the mid 2007, the 127 Special Committee, whos objective is to "standardize the new e-Loran system". e-Loran is the modernized project of LORAN-C, and it's still in phase of conceptual definition.e-Loran is meant to incorporate new antennas and signal transmission technologies that can allow Loran System to serve as an operational reserve of the Global Satellite Navigation System - G.N.S.S.

The system is in development until 2020. First eLoran station transmits, since january 2008, eLoran messages with the value of $G R I=67,310$ $\square$ s and an emisson delay of 27,300

s. The 


\section{"Mircea cel Batran" Naval Academy Scientific Bulletin, Volume XIX - 2016 - Issue 2 The journal is indexed in: PROQUEST / DOAJ / Crossref / EBSCOhost / INDEX COPERNICUS / DRJI / OAJI / JOURNAL INDEX / I2OR / SCIENCE LIBRARY INDEX / Google Scholar / Academic Keys/ ROAD Open Access I Academic Resources / Scientific Indexing Services / SCIPIO / JIFACTOR}

eLoran messages sent by this station are EUROFIX messages and contain Loran differential information, differential GPS, information regarding the integrity of the UTC referenced data.

eLoran system meets the performance, precision, disponibility and integrity ofinformation requested by the ([1], [2], [5], [18], [21]):

- air navigation at the time of aproaching landing place;

- coastal navigation in intense traffic zones, at the time of aproaching the coast line and port entry, in restricted visibility conditions;

- terrestrial navigation; terrestrial positioning;

- telecomunications and other areas of copetency (internet, ecc.) by providing UTC time referenced signals, at a precision of 50 ns.

The main advanteges of eLoran system are so defined ([1], [5], [21]):

- civic control; eLoran signal is not wilfully degraded;

- syncronized UTC transmision by an independent method form the satellite navigation systems;

- if eLorans emission is syncronized with the same UTC time source like that of the satellite systems, eLoran signal can be used combined with the satellite navigation signal;

- eLoran signal can be received also in zones that satellite system don't cover; the transmition of a real time signal (under 10 sec.) of the appearence of some faults or loss of signal integrity;

- repeatable precizion for positioning is good;

- in addition to Loran C system, eLoran has in its signal composition also a data channel that ensures the specific corrections application, integrity of information and system status warnings;

- realization and maintenance costs are lower than those of the satellite systems;

- it can be used to ensure differential corrections for satellite systems.

So that we can consider the following essential advantages of LORAN system:

- LORAN uses a high power signal and it's, almost impossible to be jammed;

- GPS is a stabil and precise system although vulnerable. LORAN can represent the GPSs oprational reserve, being completely indipendent;

\section{CONCLUSIONS}

Practical navigation experience on command deck shows that nowadays satellite navigation is the most precise and modern form of determination of the ships position. The determination error of ships position is only of a few meters.

DOI: 10.21279/1454-864X-16-12-003

(C) 2015. This work is licensed under the Creative Commons Attribution-Noncommercial-Share Alike 4.0 License.
- GPS and LORAN receivers can be used in conjunction as to raise the positioning precision level and integrity degree of this process.

General interest in maintaining and developing of LORAN system as a reserve to GNSS systems grew in the last two years, with the conturing of two fundamental vulnerabilities:the real possibility of collapse of the entire infrastructure created in base of the GPS satellite system, in the situation in which the government of the U.S. decides to deny the access to the international comunity to the modulated information emitted by the satellites, by activating code $\mathrm{Y}$; probability of low power signal jamm, although with a large broadband, of the GNSS satellites emitted signal. In essence, e-Loran uses all the Loran-C infrastructure, but introduces a data channel (in binary formatt) that are transmitted to receivers in the covering zone. In this way, e-Loran version will optimize not only the receiver technology but also the emission standards with the scope of reaching a precision of Loran point of $8 \mathrm{~m}$, providing a competitive alternative to every GNSS system.The signal transmitted by the e-Loran stations will incorporate also other types of data, the most appealing is the DGPS type. The eLoran receivers technology will permit the simultanious receiv from more Loran chains, the wanted performance is to reach 40 channels of simultanious reception.

In this context, in the years to come, the accentwill be placed on ([13], [14], [21]):

- developing aviation applications of Loran-C system;

- developing Loran-C receivers capable of processing digital signals;

- developing e-Loran comunicating capacity (especially in the transmition/reception of data domain regarding GPSs integrity and DGPS correction data);

- developing hybrid GPS/LORAN-C receivers. e-Loran receivers now use „everything in sight" reception, that incorporate signals from all satellites in the zone and incorporate also time and other data signals up from 40 channels. These improvements of Loran system responds to the necessity of developing a system as a substitute for the scenarios in which GPS system is not available or degraded. 


\section{"Mircea cel Batran" Naval Academy Scientific Bulletin, Volume XIX - 2016 - Issue 2 The journal is indexed in: PROQUEST / DOAJ / Crossref / EBSCOhost / INDEX COPERNICUS / DRJI / OAJI / JOURNAL INDEX / I2OR / SCIENCE LIBRARY INDEX / Google Scholar / Academic Keys/ ROAD Open Access I Academic Resources / Scientific Indexing Services / SCIPIO / JIFACTOR}

In navigation, the officer of watch uses especially the satellite provided information when passin through straights and when navigatin in peripheral areas with reduced navigation facilities.

Compared to the other equipments and systems onboard ships, satellite systems such as GPS/DGPS or Loran-C help the officer of watch in knowing in real-time the position of the ship.With all these, the most important element for the officer of watch, in sight of the execution of safety navigation is the knowledge and correct use of the ECDIS system, this last, offering an overall image of the navigation situation and permitts the officer of watch to interpret much easier the data provided by other equipments on board.It is true that this overview is due to the gyrocompass that provides information about the ships course, to the Loch measuring the vessels speed,to the ultrasonic probe that provides information on water depth, to the ARPA radar providing information usable either as a backup system for determining the ship's position either for viewing marine traffic or radar information that supplements the AIS system for maritime traffic.

The current trend is to invest in technology to replace the human factor with so-called safe technologies.Human factor ability to cope with technological advances requires rethinking human team responsibilities watch on the bridge.Technology must be seen as a help, a complement to the cart team.Technology can't be safer than man; it inherits, since the planning stage, the limits of those who designed and developed it.An officer on watch well prepared realizes that each navigational equipment at his disposal on the bridge is designed to help and that it may ease the work, it can increase the accuracy of its activities related to ship and fast determination and correct position on sea.

With the development of satellite navigation systems in conjunction with eLoran system a new concept was born: e-navigation. This requires a solid accuracy, availability, validity and integrity that the two concepts and systems, apparently in contradiction, are able to provide.

These two systems represent the center of gravity of modern positioning. e-Loran is an upgrade of the Loran-C system using its advantages and is defined as a solution that include UTC synchronized transmissions at least on one LORAN data channel, additional mapping and differential corrections. This is an ideal solution to serve as a complement to the GPS signal, but the eLoran signal and data transmission mode is quite different and completely independent of GPS.

Brief comparative analysis of the GPS signal and the satellite system eLoran:

\begin{tabular}{|c|c|}
\hline GPS & eLoran \\
\hline global coverage, satellite transmission & $\begin{array}{c}\text { Continental coverage but also global, terrestrial } \\
\text { transmission }\end{array}$ \\
\hline easy to block / falsify & extremely difficult to block / falsify \\
\hline L band frequency variety & low frequency spectrum protected \\
\hline low power transmission & high power transmission \\
\hline sensitive to blockage & invulnerable to jam \\
\hline it needs external antenna & signal penetrate underground and interior \\
\hline
\end{tabular}

\section{BIBLIOGRAPHY}

[1] Boșneagu R., (2013) Navigația electronică. Navigația ortodromică, Editura EX PONTO, Constanța

[2] Boșneagu R., Lupu, S., (2014), Modern hyperbolic navigation systems. Present and future, Constanta

Maritime University Annals, Year XV, Vol.21

[3] Cojocaru S., (2008), Tratat de navigație maritimă, vol. I și II, editura ARS Academica, București

[4] Lupu,S., (2011), Elemente de dinamica sistemului global de poziţionare NAVSTAR-GPS, Editura Academiei Navale "Mircea cel Bătrân", Constanţa

[5] Norris, A., (2010), ECDIS and Positioning, Integrated Bridge Systems, vol. 2, The Nautical Institute, 2010

[6] *** IMO Resolution A.819(19)/1995 Performance Standards for Shipborne Global Positioning Sysem

(GPS) Receiver Equipment

[7] *** IMOResolution A.915(22)/2001 Revised Maritime Policy and Requirements for a Future Global Navigation Satellite System (GNSS)

[8] ${ }^{* \star \star}$ Resolution MSC.112(73)/2000 Adoption of the Revised Performance Standards for Shipborne Global Positioning System (GPS) Receiver Equipment

[9] ${ }^{\star \star \star}$ Resolution MSC.113(73)/2000 Adoption of the Revised Performance Standards for Shipborne DGPS and DGGLONASS Maritim Radio Beacon Receiver Equipment

[10] ${ }^{* * *}$ Resolution MSC.114(73)/2000 Adoption of the Revised Performance Standards for Shipborne Global Positioning System (GPS) Receiver Equipment 
"Mircea cel Batran" Naval Academy Scientific Bulletin, Volume XIX - 2016 - Issue 2 The journal is indexed in: PROQUEST / DOAJ / Crossref / EBSCOhost / INDEX COPERNICUS / DRJI / OAJI / JOURNAL INDEX / I2OR / SCIENCE LIBRARY INDEX / Google Scholar / Academic Keys/ ROAD Open Access I Academic Resources / Scientific Indexing Services / SCIPIO / JIFACTOR

[11] ${ }^{\star \star \star}$ Resolution MSC.115(73)/2000 Adoption of the Revised Performance Standards for Shipborne Combined GPS/GLONASS Receiver Equipment

[12] ${ }^{* * *}$ Resolution MSC.233(82)/2006 Adoption of the Performance Standards for Shipborne GALILEO Receiver Equipment

[13] ${ }^{* * *}$ International Loran Association, Enhanced Loran (eLoran), Definition Document, 2007

[14] ${ }^{* * *}$ ILA-40, eLoran System Definition and Signal Specification Tutorial, 2011

[15] ***http://www.spacealliance.ro/

[16] ***https://linxtechnologies.com/blog/beginners-guide-satellite-navigation-systems/

[17] ${ }^{\star * \star}$ http://jproc.ca/hyperbolic/loran_c_sigchar.html

[18] ***http://www.ursanav.com/solutions/technology/eloran/

[19] ***http://www.ecdis-info.com/

[20] $\star * \star$ http://www mcanet.mcga.gov.uk

[21] ***http//www.loran.org

[22] ***http//www.loran9930.go.kr

[23] ***http//www.smrce.com

[24] ***http//www.transas.com

[25] ***http//www.uscg.mil

[26] ***https://www.glonass-iac.ru/en/ 